\title{
Cross-cultural Patterns of Attachment: A Meta-Analysis of the Strange Situation
}

\author{
Marinus H. van IJzendoorn and Pieter M. Kroonenberg
}

Universuty of Letden

\begin{abstract}
van IJzendoorn, Marinus H, and Kroonenberg, Pieter M Cross-cultural Patterns of Attachment A Meta-Analysts of the Strange Situation CHILd Development, 1988, 59, 147-156 Crosscultural research using Ainsworth's Strange Situation tends to rely on incomplete information and to concentrate on individual rather than aggregated samples In this study, a wider perspective is taken by examining almost 2,000 Strange Situation classifications obtained in 8 different countries Differences and similarities between distributions in classifications of samples are investigated using correspondence analysis Aggregation of samples per country and contment allowed for a firmer empirical basis for cross-cultural analysis Substantial intiacultural differences weie established, in a number of instances, samples from I country resembled those in other countries more than they did each other The data also suggest a pattern of cross-cultual differences, in which $A$ classifications emerge as relatıvely more prevalent in Western European countıes and $C$ classifications as relatively more frequent in Israel and Japan Intacultural vaination was nearly 15 times the crosscultural variation
\end{abstract}

Cross-cultural aspects of attachment theory and findings have been discussed for several years (Ainsworth, 1977, Bretherton, 1985, Hinde, 1982, Lamb, Thompson, Gardner, \& Charnov, 1985, Sag1 \& Lewkowlcz, 1987) Research using the Strange Situation paradigm (Ainsworth, Blehar, Waters, \& Wall, 1978) in various countries seemed to show marked differences in distributions of attachment classifications across cultures distributions found in Bielefeld, Federal Republic of Germany (Grossmann, Grossmann, Spangler, Suess, \& Unzner, 1985), in Sapporo, Japan (Miyake, Chen, \& Campos, 1985, Takahash1, 1986), and in Israelı kubbutzım (Sagı et al, 1985) were seen to deviate strongly from the American "standard" distribution of about $20 \%$ avoldant $(A), 70 \%$ secure $(B)$, and $10 \%$ resistant $(C)$ attachment relationships (Ainsworth et al , 1978) A relatively high percentage of $A$ classifications were found in Bielefeld, and a relatively high percentage of $C$ classifications, in Japan and Israel

It is somewhat currous that so much attention has been paid to deviant distributions found in these samples (see, for instance, Bretherton, 1985, Lamb et al , 1985) Because sample sizes in attachment research generally have been rather small, sampling error cannot always be ruled out In the case of the
Bielefeld sample, Hinde (1982) rightly speaks of a "provisional" finding if the obtained distribution deviates not only from the American "standard" but also from other German and Western European distributions, its characteristics need to be replicated before speculations about this population's idiosyncratic cultural background can be senously entertained

In general, cross-cultural discussions of attachment theory and findings have presupposed that there are large cross-cultural differences compared with intracultural differences, however, no empincal studies have addressed this issue on the avallable data $\mathrm{Al}$ though Lamb et al (1985, p 183), Fthenakis (1985, p 223), van IJzendoorn (1986a, p 559), and Sag1 and Lewkowicz (1987, p 432) have compared attachment classification distributions from several different cultures, at most only a third of the avallable evidence was considered in each instance, statements about the proportion of intracultural to crosscultural differences could theiefore only be imprecise For example, Lamb et al (1985) mentioned both variations of distributions between and within cultures, but they did not compare the relatively large intracultural var1ation of the United States with that of non-

The authors acknowledge the helpful comments of Willam $\mathrm{P}$ Gaidner and an anonymous reviewer on an earlier draft of this manuscript $A$ previous version was piesented at the biennial meeting of the Society for Research in Child Development, Baltimore, MD, Aprl 1987 Requests for reprints should be addressed to Marmus $\mathrm{H}$ van IJzendoorn, Department of Education, University of Leiden, P O Box 9507, NL-2300 RA Leiden, Netherlands

[Chtld Development, 1988, 59, 147-156 C 1988 by the Society for Research in Child Development, Inc All rights reserved $00093920 / 88 / 59010022 \$ 0100]$ 


\section{Child Development}

American distributions (see also, Sagi \& Lewkowicz, 1987).

Finally, it is by no means clear whether the much-discussed deviations from the American "standard" distribution are as dramatic as is often suggested. In the absence of systematic analysis of a wide range of American and non-American distributions obtained in different samples, it is impossible to evaluate whether such deviations are indeed significant or may only reflect expectable between-sample variation.

In this study we consider the largest data base of Strange Situation classifications collected so far. By comparing individual samples with a "global" distribution, derived across all available samples, a more appropriate perspective on sample-specific variations can be gained. Furthermore, by aggregating data per country or continent, the risk of capitalizing on outlying and unreliable distributions of individual samples will be lessened. Lastly, by considering not only Ainsworth et al.'s (1978) "standard" distribution but other American samples as well, it becomes possible to compare more precisely intracultural versus cross-cultural differences.

\section{Method}

Data base.-A computer search of the "Lockheed files" for the key word "attachment" as well as examination of the multinational data set compiled by Sagi and Connell (see, Sagi \& Lewkowicz, 1987) were used to identify relevant studies. The following criteria were subsequently applied in selecting the data base for the current analysis. (1) Only studies on infant-mother attachment using classical Strange Situation procedures and reporting the distribution of $A, B$, and $C$ classifications were considered; other caregiverinfant dyads, assessments by nonstandard procedures, and studies in which $A$ and $C$ classifications were reported as a single "insecure" category were excluded. (2) Special groups such as Down's syndrome children or twins were excluded, as were samples of less than $N=35$ (this latter was to avoid sampling instabilities and effects of possible misclassifications on individual sampling distributions). (3) Studies with overlapping samples were eliminated. Thus, for example, Matas, Arend, and Sroufe's (1978) sample was excluded because 11 of the 48 subjects had been included in another study; to reflect findings reported by the Minnesota Longitudinal Project in various publications, we selected only their largest sample, as described by Egeland and Farber (1984). (4) Studies involving children older than 24 months were excluded; the oldest sample included in the data base had a mean age of 21 months and came from Goossens's study (1986; see also, van IJzendoorn, Goossens, Kroonenberg, \& Tavecchio, 1985). In total, 32 samples from eight countries were selected, representing 1,990 Strange Situation classifications.

Data analyses.-The samples were cast in a contingency table, with sample $N$ 's as one of the marginal distributions and frequency of $A, B$, and $C$ classifications over all samples as the other (see Table 1). Three kinds of analyses were performed on these data.

1. To assess significant deviations in frequency of a particular classification in a given sample, standardized residuals for each cell of the table-computed as $\left[(O-E)^{2} /(E)\right]^{1 / 2}$, that is, the square root of the cell's contribution to the overall chi square or, more correct, Pearson's $\chi^{2}$-were obtained. These residuals are standardized deviations from a model of independence between rows and columns and hence provide an index of variability; under adequate assumptions, they are asymptotically standard normal distributed (see Bishop, Fienberg, \& Holland, 1975). A large standardized residual indicates that the observed cell frequency is considerably larger or, if the sign is negative, smaller than expected from the marginals. Because a large number of cells were to be evaluated (three categories $\times 32$ samples $=96$ cells), the Bonferroni approach was used to guard against capitalization on chance: the standard alpha level of .05 was divided by 96 , and a two-tailed Bonferroni alpha level of .0005 was adopted. Standardized residuals of 3.5 or larger attain this level of significance.

2. To evaluate the extent of cross- and intracultural differences, the overall variation (i.e., Pearson's $\chi^{2}$ ) was partitioned into sums of squared residuals over samples within a country and those between countries. Similarly, the variation between countries may be further partitioned into sums of squared residuals over countries within a region or continent and those between regions (see Greenacre, 1985, pp. 203-204).

3. To investigate similarities and differences in sample profiles (i.e., the distribution of relative proportions of $A, B$, and $C$ classifications), we used correspondence analysis, a technique widely used by French investigators (for details, see Benzécri, 1976; Greenacre, 1985; Nishisato, 1980). Briefly described, the method permits simultaneous 
analysis of both sample and category profiles; its solution is obtained via singular value decomposition of the standardized residuals and a weighting of the singular vectors by the square root of the singular values multiplied by the inverse square root of $N$ subjects in a sample or category.

In graphic representations of the results of this analysis (such as depicted in Fig. 1), the origin represents the marginal distributions of both categories and samples; in essence, it is the global distribution derived from all the samples, and samples close to the origin have profiles that closely resemble the global one. Distance from the origin indexes the extent to which the given sample or category distribution deviates from its marginal distribution, and the direction indicates the kind of deviation. Samples or categories that are close together resemble each other, and those that deviate in opposite directions are negatively related; when both a sample and category point are close together, the deviation from the marginal distributions is particularly pronounced in that sample-and-category combination. In sum, the representation permits seeing which samples have similar profiles over categories and which categories have similar profiles over samples, as well as which categories and which samples deviate markedly from their "global" distribution.

\section{Results}

The frequencies of $A, B$, and $C$ classifications obtained in each of the 32 samples (as well as summed over countries and regions) are shown in Table 1 . In all but one instance (Grossmann et al., 1985, labeled F2 in the table), the $B$ category emerges as modal.

Deviations from expected frequencies: standardized residuals. - Considering first the data for countries (italicized entries in Table 1), the standardized residuals are negative (smaller than expected) for the $C$ and positive (larger than expected) for the $A$ classification in all the four Western European countries; the obverse is true for Israel and Japan. In the single Chinese sample of U.S. residents, the $B$ category is less frequent than expected. Individual samples within countries that have cells with significant deviations from marginal expectations include Grossmann's Bielefeld sample (F2), in which $A$ 's are overrepresented; Sagi's Israeli kibbutzim sample (II) and Egeland and Farber's sample (U9), which are characterized by overrepresentation of C's; and the Sapporo sam- ple (J2), in which significantly fewer $A$ 's and significantly more $C$ 's were found.

Intracultural versus cross-cultural differences: partitioning variation.-In our data base, differences between samples, $\chi^{2}(62, N$ $=1,990)=248.6, p<.0001$; between countries, $\chi^{2}(14, N=1,990)=102.4, p<.0001$; and between continents, $\chi^{2}(6, N=1,990)=$ 92.1, $p<.0001$, are significant. Differences between samples within the Federal Republic of Germany, $\chi^{2}(4, N=136)=16.5, p$ $<.01$; within Japan, $\chi^{2}(2, N=96)=9.6, p<$ .01 ; and within the United States, $\chi^{2}(34, N=$ $1,230)=102.8, p<.0001$, are significant as well. Differences between samples within Israel, $\chi^{2}(2, N=118)=5.9, p=.05$, and within the Netherlands, $\chi^{2}(6, N=251)=11.2, p=$ .08 , are only marginally significant. Differences between the distributions of the nonU.S. countries and the United States itself are negligible, $\chi^{2}(2, N=1,990)=.3$; N.S.

To acquire some indication of the relative size of the intracultural and cross-cultural differences, the total variation (i.e., Pearson's $\chi^{2}$ ) of Table 1 is partitioned into parts associated with countries and continents (see Table 2).

The most salient aspect of Table 2 is that the intracultural variation (i.e., within countries) is nearly 1.5 times the cross-cultural variation (i.e., between countries). The average variation per sample within countries is especially large in the Federal Republic of Germany (6.2) and the United States (5.8) and much smaller in the Netherlands (2.7) and Japan (2.7). For Great Britain, Sweden, and the (American) Chinese sample this can, of course, not be assessed. The contributions of German and Dutch samples to the betweencountry variation are about the same as their within-country variation. As will be seen in more detail later, the within-U.S. variation is such that the United States has an $A, B, C$ distribution closely resembling the global distribution. On the average, the Japanese and Israeli samples contribute most to the between-countries and between-continent variation. The Western European countries have relatively similar profiles: of the betweencountries variation of 4.6 per sample, only a quarter (1.1) is associated with the differences among themselves, whereas the rest (3.5) is associated with differences with (countries from) other continents.

Similarities and differences in profiles: correspondence analysis.-A correspondence analysis was carried out to get an overview of the structural similarities and differences 


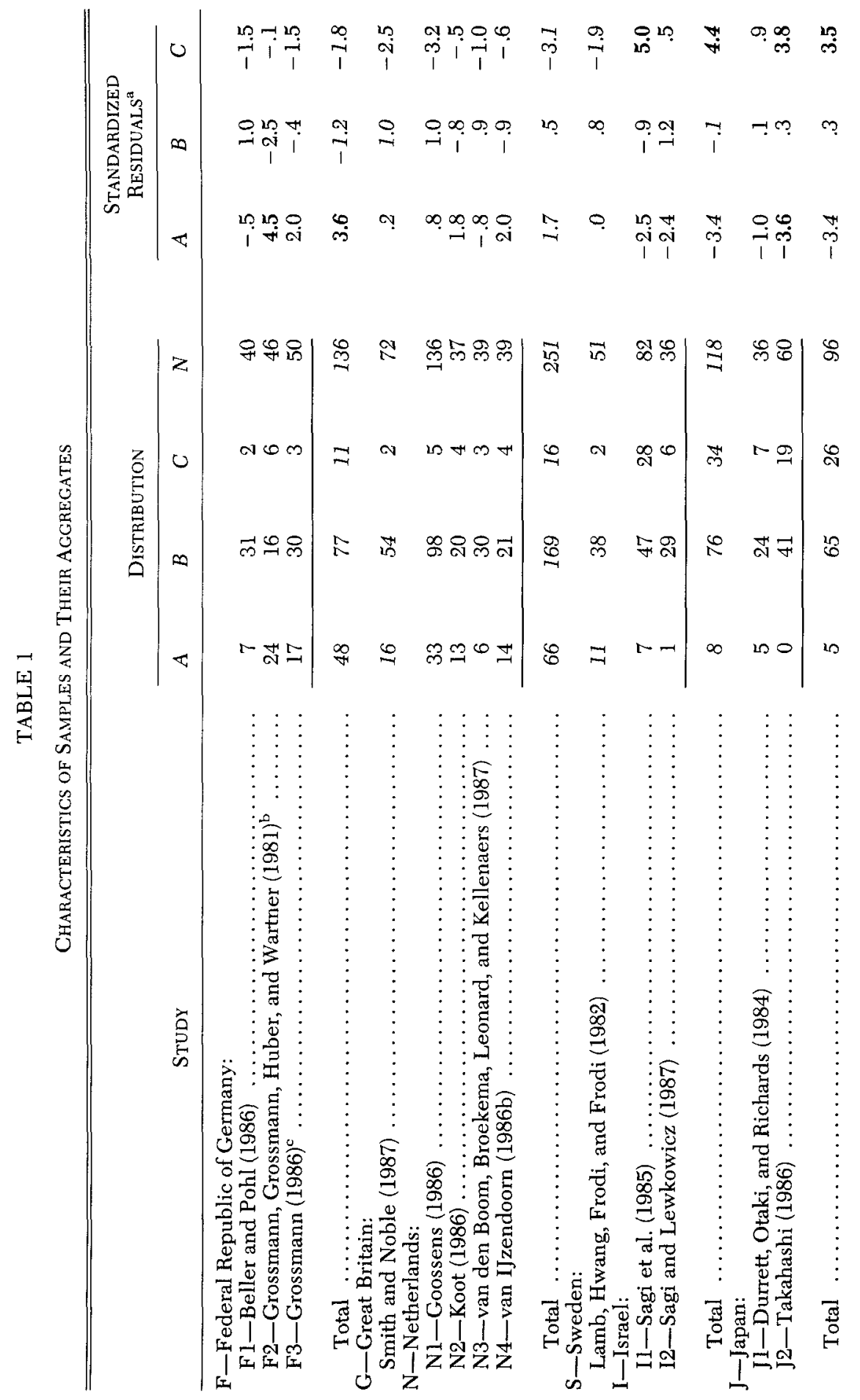




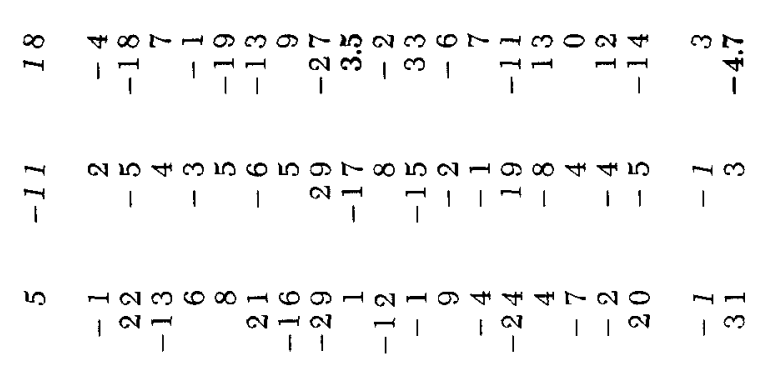

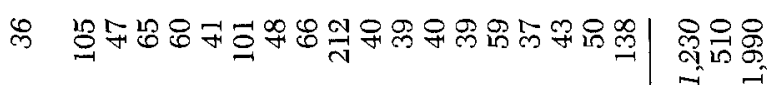

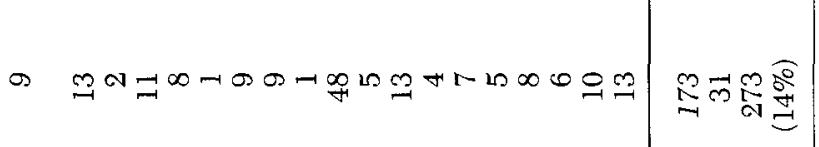

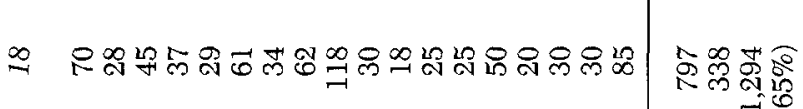

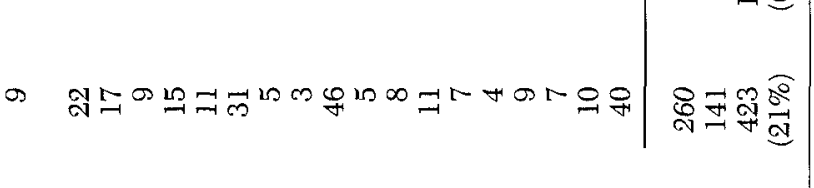

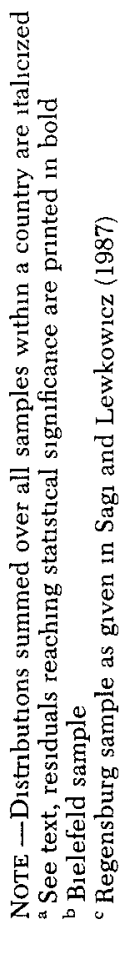




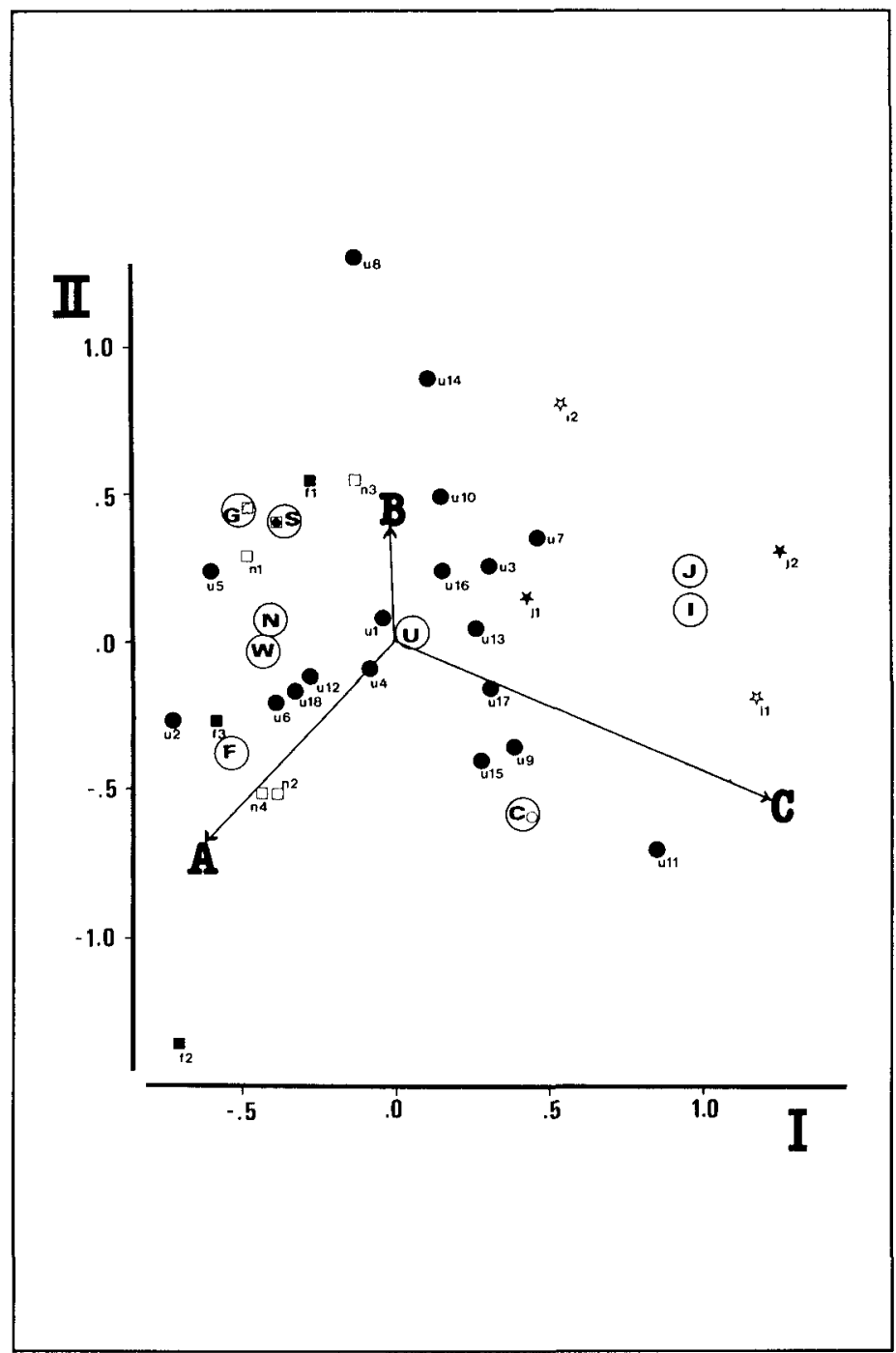

FIG. 1.-Correspondence analysis solution of sample-by-classification table. Arrows indicate classification categories. Points indicate samples; for labels see Table 1.

between profiles of individual samples (see Fig. 1).

In Figure 1, the U.S. samples show very large variation, but their center of gravity is near the origin of the figure, indicating a U.S. distribution nearly proportional to the global one. ${ }^{1}$ Ainsworth et al.'s (1978) "standard" sample (U1) is also projected near the origin.

In other countries, too, intracultural variation is rather large compared with crosscultural variation. In Germany, for example, the distance between the Berlin (F1) and

${ }^{1}$ In this figure, the countries (and Western Europe) have been projected by using regressiontype procedures with the country coordinates as the criteria and the category coordinates as regression weights for the frequencies of the countries. In other words, countries are treated as "variables supplémentaires." Greenacre (1985, pp. 202-203), among others, shows that these country (continent) points lie in the center of gravity of the samples from that country (continent). The same procedure may be used for $A, B$, and $C$ frequency distributions $\left(f_{A}, f_{B}, f_{C}\right)$ of new samples. Therefore, researchers can project their distributions into our Figure 1 by using the following formulas for the $X$-coordinate and $Y$-coordinate, respectively: $X=\left(-.6447 f_{A}-.0313 f_{B}+1.1473 f_{C}\right) /(.2696 \times$ $N)$, and $Y=\left(-.7031 f_{A}+.3495 f_{B}-.5670 f_{C}\right) /(.2286 \times N)$, where $N=f_{A}+f_{B}+f_{C}$. 
TABLE 2

Between and Within Partitioning of Total Variation $\left(\chi^{2}\right)$ of the Samples-by-Categories CONTINGENCY TABLE

\begin{tabular}{|c|c|c|c|c|c|c|}
\hline \multirow[b]{2}{*}{ COUNTRY } & \multicolumn{3}{|c|}{ PARTITIONING OF $\chi^{2}$} & \multicolumn{3}{|c|}{$\begin{array}{c}\text { AVERAGE } \\
\text { VARIATION PER SAMPLE }^{\text {b }}\end{array}$} \\
\hline & Between & Within & Total & Between & Within & Total \\
\hline Federal Republic of Germany & 176 & 187 & 364 & 59 & 62 & 121 \\
\hline Great Britain & 73 & 0 & 73 & 73 & 0 & 73 \\
\hline Netherlands & 128 & 108 & 236 & 32 & 27 & 59 \\
\hline Sweden & 43 & 0 & 43 & 43 & 0 & 43 \\
\hline Israel & 309 & 86 & 395 & 155 & 43 & 198 \\
\hline Japan & 239 & 54 & 293 & 120 & 27 & 147 \\
\hline United States & 1 & 1034 & 1035 & 0 & 58 & 58 \\
\hline Chinese & 47 & 0 & 47 & 47 & 0 & 47 \\
\hline Western Europe & 318 & 103 & 421 & 35 & 11 & 46 \\
\hline Total & 1024 & 1462 & 2486 & 32 & 46 & 78 \\
\hline
\end{tabular}

Brelefeld (F2) sample is about as large as the distance between the Berlın sample and the Israelı kıbbutzım (I1) or the Kennedy and Bakeman sample (U11) In Japan, the Tokyo sample (J1) resembles Crockenberg's (U7) and Bates's (U3) samples more than the Sapporo sample (J2) The Israel city sample (I2) resembles Owen's sample (U14) more than the Israelı kıbbutzım sample (I1), which shows more similarity to the Kennedy and Bakeman sample (U11)

Even though the standardized resıduals of the Easterbrooks and Lamb sample (U8) were not extreme (see Table 1), its outlying position in Figure 1 is due to its unusual profile The B1elefeld (F2) and Sapporo (J2) samples are clearly outliers as well

There is no common usage to inspect dimensions in correspondence analysis, but one may discern that the first dimension (variation $=1446$ or $58 \%$ ) shows a progression of an overrepresentation of the $A$ classifications on the left to an overrepresentation of the $C$ classifications on the right, while the second dimension (variation $=1040$ or $42 \%$ ) ind cates a $B$ versus $A$ plus $C$ overrepresentation The former trend roughly corresponds with the division Western Europe (W) versus the United States (U) versus Japan (J) and Israel (I) on the first dimension The overrepresentation of $A$ and $C$ dyads characterizes a cluster of low socioeconomic status samples the Kennedy and Bakeman (U11), Egeland and Farber (U9), and Schneider-Rosen and Cic- chettı (U15) samples, as well as Li-Repac's Chinese sample (C)

\section{Discussion}

Based on evidence of the 32 studies considered in this analysis, intracultural differences emerge as being quite considerable Seeing that often it is the same investigator who obtained samples with widely different distributions within a given country (e g , Federal Republic of Germany, United States, Israel), such intracultural variation can hardly be attributed to differences in procedures or application of the coding system (Lamb et al , 1985)

Although when aggregated over the 18 samples, the US distribution is proportional to the "global" pattern derived from all samples (as 1s, fortuitously, Ainsworth et al's 1978 sample distribution, U1), its status as a "standard" is achieved only through aggregation over a wide diversity Thus, for instance, Easterbrooks and Lamb's sample (U8) differs notably from Kennedy and Bakeman's (U11), Egeland and Farber's (U9), and SchneiderRosen and Cicchettı's (U15), there are very few anxiously attached dyads in the former and very many (particularly C's) in all the latter The Easterbrooks and Lamb sample consisted of middle-class, mostly professional families, in contrast, the other three all involved low socioeconomic status and included, respectively, black infants from a low-income population, economically disadvantaged and maritally unstable families, 


\section{Child Development}

and a number of maltreated infants Effects of environmental stress appear implicated as at least one factor in leading to such extreme differences (see Vaughn, Egeland, Sroufe, \& Waters, 1979)

It is also evident that some of the U S samples resemble non-U S ones more closely than they do each other Thus, Owen et al's sample (U14) is most like the Israeli city sample (I2), whereas Antonucci and Levitt's (U2) resembles at most two of the Dutch samples (N4 and N2), as well as Grossmann's Regensburg group (F3) Similar findings apply to other countries in Japan, the Tokyo distribution (J1) is more like Bates et al 's (U3) and Crockenberg's (U7) distributions than it is like the Sapporo sample (J2), in Germany, the Regensburg (F3) and Berlin (F1) distributions correspond more closely to those of other Western European countries than to the Bielefeld (F2) sample, which is shown as an extreme outlier in Figure 1 It is clear that great caution should be exercised in assuming that an individual sample is representative of a particular (sub)culture and that the eccentric status of an "outlier" distribution should awat replication before it is brought to bear on cross-cultural debates

Some cross-cultural (as opposed to intracultural) similarities and differences are also suggested by the data As to the former, it is evident that the $B$ classification is modal in all countries, however, whether or not this implies that patterns of secure attachments (as understood in US research) predominate in all rearing environments cannot be established in the absence of data obtained outside the Strange Situation The overall pattern of among-country differences suggests greater relative frequency of $A$ classifications in Western European countries and of $C$ classifications in Israel and Japan, with the U S distribution falling in-between these two poles

Intracultural differences are 15 times as large as cross-cultural differences Only the Japanese and Israeli samples and Western Europe as a whole contribute more to the cross-cultural variation than to the intracultural variation, while the US samples contribute only to the intracultural variation In fact, the global distribution would hardly change if the US samples would not be taken into account After all, the differences between the distributions of the non-U S and US samples are nearly zero Therefore, given that the Strange Situation is a valid instrument for measuring attachment quality in the United States, there is no reason to doubt its cross-cultural validity only because crosscultural sample distributions differ from Ainsworth et al 's (1978) "standard"

The relatively modest cross-cultural differences may reflect the effects of mass media, particularly in the Western world, where television programs and books that advocate similar notions of parenting are disseminated across countries It seems evident that data from less Western-onented cultures such as Africa, South America, and Eastern European socialist countries will be needed to establish a more truly global and betterinformed cross-cultural perspective on inferences to be derived from differences in distributions of Strange Situation attachment classifications

\section{References}

Ainsworth, M D S (1977) Attachment theory and its utility in cross-cultural research In $\mathrm{P} \mathrm{H}$ Leiderman, S R Tulkın, \& A Rosenfeld (Eds), Culture and infancy Vartations in the human experience (pp 49-67) New York Academic Press

Ainsworth, M D S, Blehar, M C, Waters, E , \& Wall, S (1978) Patterns of attachment, a psychological study of the Strange Sttuation Hillsdale, NJ Erlbaum

Antonucc1, T C, \& Levitt, M J (1984) Early prediction of attachment security A multivariate approach Infant Behavior and Development, $7,1-18$

Bates, J E, Maslın, C A , \& Frankel, K A (1985) Attachment securty, mother-child interaction, and temperament as predictors of behaviorproblem ratings at age three years In I Bretherton \& E Waters (Eds), Growing points of attachment theory and research Monographs of the Society for Research in Child Development, 50(1-2, Serial No 209), 167193

Beller, E K, \& Pohl, A (1986, Aprl) The Strange Situation revisited Paper presented at the Fourth International Conference on Infant Studies, Beverly Hills, CA

Belsky, J , Rovine, M , \& Taylor, D G (1984) The Pennsylvania Infant and Family Development Project, III The origins of individual differences in infant-mother attachment Maternal and infant contributions Child Development, $\mathbf{5 5}, 718-728$

Benn, R K (1985, Aprll) Factors associated with securty of attachment in dual career familes Paper presented at the biennual meeting of the Society for Research in Chuld Development, Toronto

Benzecri, J P et Collaborateurs (1976) Analyse 
des donnees II-Analyse des correspondances [Data analysis II-Correspondence analysis] Paris Dunod

Bishop, Y Y, Fienberg, S E, \& Holland, P W (1975) Discrete multwariate analysts Theory and practice Cambridge, MA MIT Press

Bretherton, I (1985) Attachment theory Retrospect and prospect In I Bretherton \& $\mathrm{E}$ Waters (Eds), Growing points of attachment theory and research Monographs of the Society for Research in Child Development, 50(1-2, Serial No 209), 3-37

Connell, D B (1977) Individual differences in attachment behavior Long-term stabilty and relationship to language development (Doctoral dissertation, Syracuse University, Syracuse, NY) (University Microfilms, No 77-30, 717)

Crockenberg, S B (1981) Infant imtability, mother responsiveness, and social support influences on the security of infant-mother attachment Chald Development, 52, 857-865

Durrett, M E, Otakı, M , \& Richards, P (1984) Attachment and the mother's perception of support from the father International Journal of Behavioral Development, 7, 167-176

Easterbrooks, M A, \& Lamb, M E (1979) The relationship between quality of infant-mother attachment and infant competence in initial encounters with peers Child Development, 50, 380-387

Egeland, B , \& Farber, E A (1984) Infant-mother attachment Factors related to its development and changes over time Child Development, 55, 753-771

Frodi, A , \& Thompson, R (1985) Infant's affective responses in the Strange Situation Effects of prematurity and of quality of attachment Child Development, 56, 1280-1290

Fthenakıs, W E (1985) Vater Band I Zur Psychologie der Vater-Kind Bezıehung [Fathers Volume I The psychology of father-chld relationships] Munıch Urban \& Schwarzenberg

Goossens, F A (1986) The quality of attachment relationships of two-year-old children of working and nonworking mothers and some assoctated factors (Doctoral dissertation, University of Leiden, Netherlands)

Greenacre, M J (1985) Theory and applications of correspondence analysts London Academic Press

Grossmann, K E, Grossmann, K, Huber, F, \& Wartner, U (1981) German chlldren's behavlor towards their mothers at 12 months and their fathers at 18 months in Answorth's Strange Situation International Journal of $\mathrm{Be}$ havioral Development, 4, 157-181

Grossmann, K, Grossmann, K E, Spangler, G, Suess, G, \& Unzner, L (1985) Maternal sensitivity and newborns' onentation responses as related to quality of attachment in Northern Germany In I Bretherton \& E Waters (Eds), Glowing points of attachment theory and research Monographs of the Society for Research in Child Development, 50(1-2, Serial No 209), 233-256

Hinde, R A (1982) Attachment Some conceptual and brological issues In J Stevenson-Hinde \& C Murray Parkes (Eds), The place of attachment in human behavior (pp 60-78) New York Basic Books

Kennedy, J H , \& Bakeman, R (1984) The early mother-infant relationship and social competence with peers and adults at three years Journal of Psychology, 116, 23-34

Koot, J M (1986, November) De spanningsregulering van veulig en onverlig gehechte kinderen na blokkering van hun spel door de moeder [Tension regulation of anxiously and securely attached children after blocking of their play] Paper presented at the Dutch Conference of Psychologists, Groningen, Netherlands

Lamb, M E , Hwang, C P, Frodl, A, \& Frod, M (1982) Security of mother- and father-infant attachment and its relation to sociability with strangers in traditional and non-traditional Swedish families Infant Behavior and Development, 5, 355-367

Lamb, M E, Thompson, R A, Gardner, W, \& Charnov, E L (1985) Infant-mother attachment The ongins and developmental significance of individual differences in Strange Situation behavior Hillsdale, NJ Erlbaum

Li-Repac, D C (1982) The impact of acculturation on the child-rearing attitudes and practices of Chinese-American families Consequences for the attachment process (Doctoral dissertation, University of Calıforma, Berkeley)

Main, M (1983) Exploration, play, and cognitive functroning related to infant-mother attachment Infant Behavior and Development, 6, $167-174$

Matas, L, Arend, R A, \& Sroufe, L A (1978) Continuity of adaptation in the second year The relationship between quality of attachment and later competence Child Development, 49, 547-556

Miyake, K, Chen, S -J , \& Campos, J J (1985) Infant temperament, mother's mode of interacton, and attachment in Japan An interm report In I Bretherton \& E Waters (Eds), Growing points of attachment theory and research Monographs of the Soctety for Research in Child Development, 50(1-2, Serial No 209), 276-297

Moss, A L (1979) Parent-child interaction, attachment, and competence A study of interrelationships (Master of arts thesis, University of Texas at Austın) 
Nishisato, S. (1980). Analysis of categorical data: Dual scaling and its applications. Toronto: University of Toronto Press.

Owen, M. T., Easterbrooks, M. A., Chase-Lansdale, L., \& Goldberg, W. A. (1984). The relation between maternal employment status and the stability of attachments to mother and to father. Child Development, 55, 1894-1901.

Sagi, A., Lamb, M. E., Lewkowicz, K. S., Shoham, R., Dvir, R., \& Estes, D. (1985). Security of infant-mother, father, metapelet attachments among kibbutz-reared Israeli children. In I. Bretherton \& E. Waters (Eds.), Growing points of attachment theory and research. Monographs of the Society for Research in Child Development, 50(1-2, Serial No. 209), 257275.

Sagi, A., \& Lewkowicz, K. S. (1987). A crosscultural evaluation of attachment research. In L. W. C. Tavecchio \& M. H. van IJzendoorn (Eds.), Attachment in social networks. Contributions to the Bowlby-Ainsworth attachment theory (pp. 427-459). Amsterdam: Elsevier Science.

Schneider-Rosen, K., \& Cicchetti, D. (1984). The relationship between affect and cognition in maltreated infants: Quality of attachment and the development of visual self-recognition. Child Development, 55, 648-658.

Smith, P. K., \& Noble, R. (1987). Factors affecting the development of caregiver-infant relationships. In L. W. C. Tavecchio \& M. H. van IJzendoorn (Eds.), Attachment in social networks. Contributions to the BowlbyAinsworth attachment theory (pp. 93-134). Amsterdam: Elsevier Science.

Takahashi, K. (1986). Examining the Strange Situation procedure with Japanese mothers and 12- month-old infants. Developmental Psychology, 22, 265-270.

Thompson, R. A., \& Lamb, M. E. (1983). Security of attachment and stranger sociability in infancy. Developmental Psychology, 19, 184-191.

van den Boom, D. C., Broekema, A., Leonard, S., \& Kellenaers, C. J. J. (1987). Individual differences in attachment behavior in a Dutch sample: Stability and its relationship to changing. life circumstances. Leiden: Department of Psychology.

van IJzendoorn, M. H. (1986a). The cross-cultural validity of the Strange Situation from a Vygotskian perspective. Behavioral and Brain Sciences, 9, 558-559.

van IJzendoorn, M. H. (1986b, November). Stand van zaken en toekomst van het onderzoek naar gehechtheidsrelaties [State of the art and future of attachment research]. Paper presented at the Dutch Conference of Psychologists, Groningen, Netherlands.

van IJzendoom, M. H., Goossens, F. A., Kroonenberg, P. M., \& Tavecchio, L. W. C. (1985). Dependent attachment: B-4 children in the Strange Situation. Psychological Reports, 57, 439-451.

Vaughn, B., Egeland, B., Sroufe, L. A., \& Waters, E. (1979). Individual differences in infant-mother attachment at twelve and eighteen months: Stability and change in families under stress. Child Development, 50, 971-975.

Waters, E. (1978). The reliability and stability of individual differences in infant-mother attachment. Child Development, 49, 483-494.

Weston, D. R. (1983). Implications of mother's personality for the infant-mother attachment relationship. (Doctoral dissertation, University of California, Berkeley). 